\title{
Oviposition ecology and species composition of Aedes spp. and Aedes aegypti dynamics in variously urbanized settings in arbovirus foci in southeastern Côte d'Ivoire
}

\author{
Julien B.Z. Zahouli, 1,2,4, Jürg Utzinger ${ }^{3,4}$, Maurice A. Adja' ${ }^{1}$, Pie Müller ${ }^{3,4}$, David Malone ${ }^{5}$, Yao Tano ${ }^{1,6}$
} and Benjamin G. Koudou, ${ }^{6,7^{*}}$

\begin{abstract}
Background: Aedes mosquito-transmitted outbreaks of dengue and yellow fever have been reported from rural and urban parts of Côte d'Ivoire. The present study aimed at assessing Aedes spp. oviposition ecology in variously urbanized settings within arbovirus foci in southeastern Côte d'Ivoire.

Methods: Aedes spp. eggs were sampled using a standard ovitrap method from January 2013 to April 2014 in different ecosystems of rural, suburban and urban areas. Emerged larvae were reared until the adult stage for species identification.
\end{abstract}

Results: Aedes spp. oviposition ecology significantly varied from rural-to-urban areas and according to the ecozones and the seasons. Species richness of Aedes spp. gradually decreased from rural (eight species) to suburban (three species) and urban (one species) areas. Conversely, emerged adult Aedes spp. mean numbers were higher in the urban (1.97 Aedes/ ovitrap/week), followed by the suburban (1.44 Aedes/ovitrap/week) and rural (0.89 Aedes/ovitrap/week) areas. Aedes aegypti was the only species in the urban setting (100 \%), and was also the predominant species in suburban (85.5 \%) and rural (63.3 \%) areas. The highest Ae. aegypti mean number was observed in the urban (1.97 Ae. aegypti/ovitrap/week), followed by the suburban (1.20 Ae. aegypti/ovitrap/week) and rural (0.57 Ae. aegypti/ovitrap/week) areas. Aedes africanus (9.4\%), Ae. dendrophilus (8.0\%), Ae. metallicus (1.3\%) in the rural, and Ae. vittatus (6.5\%) and Ae. metallicus (1.2\%) in the suburban areas each represented more than $1 \%$ of the total Aedes fauna. In all areas, Aedes species richness and abundance were higher in the peridomestic zones and during the rainy season, with stronger variations in species richness in the rural and in abundance in the urban areas. Besides, the highest Culex quinquefasciatus abundance was found in the urban areas, while Eretmapodites chrysogaster was restricted to the rural areas.

Conclusions: Urbanization correlates with a substantially higher abundance in Aedes mosquitoes and a regression of the Aedes wild species towards a unique presence of Ae. aegypti in urban areas. Aedes wild species serve as bridge vectors of arboviruses in rural areas, while Ae. aegypti amplifies arbovirus transmission in urban areas. Our results have important ramifications for dengue and yellow fever vector control and surveillance strategies in arbovirus foci in southeastern Côte d'Ivoire.

Keywords: Arboviruses, Aedes, Oviposition ecology, Culex, Eretmapodites, Ovitrap, Socio-ecological survey, Urbanization, Côte d'lvoire

\footnotetext{
* Correspondence: benjaminkg@yahoo.fr

${ }^{6}$ Université Nangui-Abrogoua, Abidjan, Côte d'Ivoire

${ }^{7}$ Filariasis Programme Support Unit from Liverpool School of Tropical

Medicine, Liverpool, UK

Full list of author information is available at the end of the article
}

\section{Biomed Central}

(c) 2016 The Author(s). Open Access This article is distributed under the terms of the Creative Commons Attribution 4.0 International License (http://creativecommons.org/licenses/by/4.0/), which permits unrestricted use, distribution, and reproduction in any medium, provided you give appropriate credit to the original author(s) and the source, provide a link to the Creative Commons license, and indicate if changes were made. The Creative Commons Public Domain Dedication waiver (http://creativecommons.org/publicdomain/zero/1.0/) applies to the data made available in this article, unless otherwise stated. 


\section{Background}

Several Aedes mosquito species are involved in the transmission of arboviral diseases, including dengue and yellow fever, responsible for major health burdens worldwide [1-3]. In the mid-1990s, yellow fever was controlled in Francophone Africa by vaccination while both yellow fever and dengue were eliminated in the Americas by effective control of Aedes aegypti [4]. However, in recent years, there has been a dramatic resurgence of dengue fever worldwide [5-8] and re-emergence of yellow fever in some parts of Africa [9]. In addition, other arboviruses vectored by Aedes mosquitoes, such as chikungunya [10], Rift valley fever [11] and Zika virus [12] are emerging or re-emerging in Africa, particularly in West Africa [13-15]. The patterns of arboviral disease transmission and its geographic expansion are likely a result of intensive urbanization $[1,2,6,16]$. However, dengue and yellow fever originated in enzootic (sylvatic) cycles associated with wild Aedes vectors in rural areas. Enzootic cycles are linked to urban transmission cycles by a major domestic vector, Ae. aegypti [17].

In Côte d'Ivoire, single and dual epidemics of dengue and yellow fever involving several wild Aedes species and the major urban vector, Ae. aegypti, have been reported in both rural and urban areas [18]. Sylvatic dengue virus circulation, without human infections, was documented by isolation of DENV-2 serotype from wild Aedes vectors, including Aedes africanus, Aedes furcifer, Aedes luteocephalus, Aedes opok and Aedes vittatus in rural areas in the 1980s [19]. Since then, several sporadic outbreaks of dengue DENV-1, DENV-2 and DENV-3 serotypes and yellow fever sometimes resulting in fatal outcomes have occurred [20-22]. The outbreaks were mostly concentrated in surrounding villages and periurban areas of Abidjan, the economic capital and the most densely populated city of Côte d'Ivoire [21, 22].

The comprehension of the shaping patterns of immature Aedes mosquito ecology along the urbanization gradient is of paramount importance in determining their role in maintenance of epidemic arboviral diseases transmission [1, 2]. Knowledge of such patterns may therefore enable a more effective deployment of vector control measures for the benefit of public health. Aedes mosquitoes are readily adapted to a broad range of ecological settings and are expected to vary according to natural and urbanized environment [2, 9]. Certain Aedes mosquito species are confined and limited to sylvatic, rural or urban areas, whereas others have a large distribution and colonize almost every environment, such as the wild, rural and urbanized settings, the domestic and peridomestic premises, the types of landscapes and the microhabitats [2,9]. Those species of Aedes occurring in transitional environments may serve as bridge vectors between enzootic diseases and humans in rural areas.
Moreover, Aedes mosquitoes are the main reservoirs of arboviruses and the longest link of the transmission chain since they host the viruses during longer duration compared to humans and wild animals [23]. These Aedes vector species show both oral and transovarial infection $[23,24]$. The extent to which eggs are resistant against desiccation varies between species and strains, and depends on climatic conditions $[25,26]$. Otherwise, Aedes mosquito species can be associated with other mosquito species for different interaction purposes such as predation, competition and symbiosis [9]. Eretmapodites chrysogaster is a predaceous mosquito and lays its eggs in Aedes species breeding sites [27]. Aedes and Culex species, mainly Culex quinquefasciatus and Ae. aegypti, are sympatric and co-occur in the same containers [28].

Aedes aegypti is an urban species and a major vector of dengue and yellow fever by amplifying epidemics among the urban populations [9, 17]. This species consists of two subspecies, Ae. aegypti aegypti and Ae. aegypti formosus that are morphologically [29], behaviourally and genetically distinct [30-32]. However, there are ambiguities resulting in confusion over morphological distinction between the two subspecies of $A e$. aegypti in West Africa [13, 33].

Urbanization could potentially modify Aedes mosquito ecology by changing the composition and dynamics of species, and increasing the abundance of their breeding sites due to environmental changes, and thus contribute to arbovirus outbreaks [2]. However, Aedes mosquito egg laying ecology is unknown in arbovirus foci located in variously urbanized settings of southeastern Côte d'Ivoire. To fill this gap, our study explored Aedes mosquito egg laying patterns, species composition and dynamics in Ehania-V1, Blockhauss and Treichville representing rural, suburban and urban settings of southeastern Côte d'Ivoire, respectively. Because immature mosquitoes are sensitive to environmental changes [2, 25, 26], we hypothesized that Aedes mosquito oviposition ecology and species composition, and the dynamics of Ae. aegypti change from rural to suburban and urban settings. Field surveys of Aedes mosquito egg were performed using a highly sensitive sampling method, namely the standardized World Health Organization (WHO) ovitraps [23, 24], larval rearing in the laboratory and adult stage identification were conducted to test our hypothesis. The findings provide valuable information on Aedes mosquito egg laying patterns, species composition and Ae. aegypti dynamics in different urbanized ecosystems. The key results open new perspectives for improving current vector control and surveillance strategies for dengue and yellow fever that are tailored for specific settings of southeastern Côte d'Ivoire. 


\section{Methods}

\section{Study area}

The study was conducted in three settings in southeastern Côte d'Ivoire: Ehania-V1, Blockhauss and Treichville, representing rural, suburban and urban areas, respectively (Fig. 1). The village of Ehania-V1 $\left(5^{\circ} 18^{\prime} \mathrm{N}, 3^{\circ} 04^{\prime} \mathrm{W}\right)$ belongs to the district of Aboisso some $140 \mathrm{~km}$ east of Abidjan. Ehania-V1 is a rural area with a population density of approximately 48 people $/ \mathrm{km}^{2}$ and unpaved roads. The residencies are composed of traditional and ordinarily modern houses. This area is surrounded by industrial oil palm plantation (Elaesis guineensis) of 11,444 ha and 100 ha of preserved primary rainforest. The rainforest provides strong vegetation with dense canopy cover, trees with holes and bamboos and hosts non-human primates and birds.

Blockhauss $\left(5^{\circ} 19^{\prime} \mathrm{N}, 4^{\circ} 00^{\prime} \mathrm{W}\right)$ is located within Abidjan bordered in its northern part by Banco National Park with over 3750 ha of rainforest. This setting is a suburban area with approximately 750 people $/ \mathrm{km}^{2}$ and paved roads. The land use comprises a mixture of residential buildings, hospitals and schools. The residencies are ordinarily modern houses and some blocks with flats. Urbanization is underway in untapped spaces.

Treichville $\left(5^{\circ} 18^{\prime} \mathrm{N}, 4^{\circ} 00^{\prime} \mathrm{W}\right)$ is situated in central Abidjan and separated from Blockhauss by the Ebrié Lagoon that has a width of approximately $4 \mathrm{~km}$. This setting is an urban area with more than 1800 people $/ \mathrm{km}^{2}$ and paved roads. The density of the population greatly increases during the daytime due to the convergence of people from other municipalities of Abidjan for trading, businesses and sports. The land use is essentially residential, commercial, cultural and sportive buildings, seaport, and public services such as schools and hospitals, filled with green spaces set apart. The residencies are mostly composed of blocks of flats and some ordinarily modern houses. Urbanization is completed due to the lack of availability of additional space for the construction of new houses.

In southeastern Côte d'Ivoire, the climate is warm and humid and overall, transitional from equatorial to tropical with four seasons. The seasons are more clearly distinguished by rainfall than temperature. The two rainy seasons are separated by a dry season. The main rainy season extends from May to July, while a short rainy season occurs in October and November. The main dry season extends from December to April. This classic sequence of seasonality has been disrupted due to strong climate variability [34]. The average annual precipitation ranges from 1200 to $2400 \mathrm{~mm}$. The annual temperature is around $26.5{ }^{\circ} \mathrm{C}$ and the annual relative humidity ( $\mathrm{RH}$ ) ranges between 78 and $90 \%$.

\section{Design of sample collection}

Aedes spp. eggs were sampled using the standard WHO ovitrap method [23, 24]. Ovitraps were metallic boxes cut with $400 \mathrm{~cm}^{3}$ volume and covered with black paint to attract gravid female Aedes mosquitoes in search of egg laying grounds. They were filled (75 \% full) with distilled water mixed with rainwater and $10 \%$ infusions of herbs (Panicum maximum) to increase the attractiveness of the ovitraps [35]. A $5 \times 7 \times 0.3 \mathrm{~cm}$ paddle made of hardboard, rough on one side and serving as oviposition substrate, was plunged in each box and left for a one-week period during each of six surveys. The rural area was divided into three ecozones: domestic, peridomestic and sylvatic. The suburban and urban areas were divided into domestic and peridomestic zones because there were no sylvatic zones. According to Cordellier et al. [23], domestic zone refers to the human-inhabited space, the peridomestic zone covers the vegetated environment surrounding the domestic zone in which humans usually discard artificial items that serve as breeding sites for Aedes mosquitoes, the sylvatic zone is primarily an undisturbed environment free of discarded containers that host forests with natural containers (e.g. tree holes) and wild animals. In our study, the peridomestic zone extended from the edge of the domestic zone to $300 \mathrm{~m}$, while the sylvatic zone was located from 300 to $800 \mathrm{~m}$ around the village. During each of the six surveys, 50 ovitraps were repeatedly placed in the same location in each defined ecozone. In the human-inhabited zone, the ovitraps were suspended at $1.5 \mathrm{~m}$ above the ground to secure and protect them. In total, 900, 600 and 600 ovitraps were deployed in the rural, suburban and urban areas, respectively, from January 2013 to April 2014. In addition, from April to July 2013, we conducted socioecological investigations in 50 households representative of each study area in which ovitraps were placed to identify their sociogeographic status.

\section{Key socio-geographic characteristics}

The socio-ecological investigations showed that the surveyed households varied highly along the increasing urbanization gradient. The mean number (mean \pm standard error) of people per household was $5.9 \pm 2.8$ in the rural, $8.6 \pm 2.1$ in the suburban and $11.9 \pm 3.2$ in the urban areas. The potential resident containers were mainly discarded items (cans, pots, barrels, tyres) $(n=50 ; 58.0 \%)$ and natural containers (coconut, tree hole, bamboo, snail shell) (46.0 \%) in the rural area. The containers were mostly artificial and discarded receptacles with 78.0 and $92.0 \%$ in the suburban and urban areas, respectively. The households stored water in the proportions of $88.0 \%(n=$ 


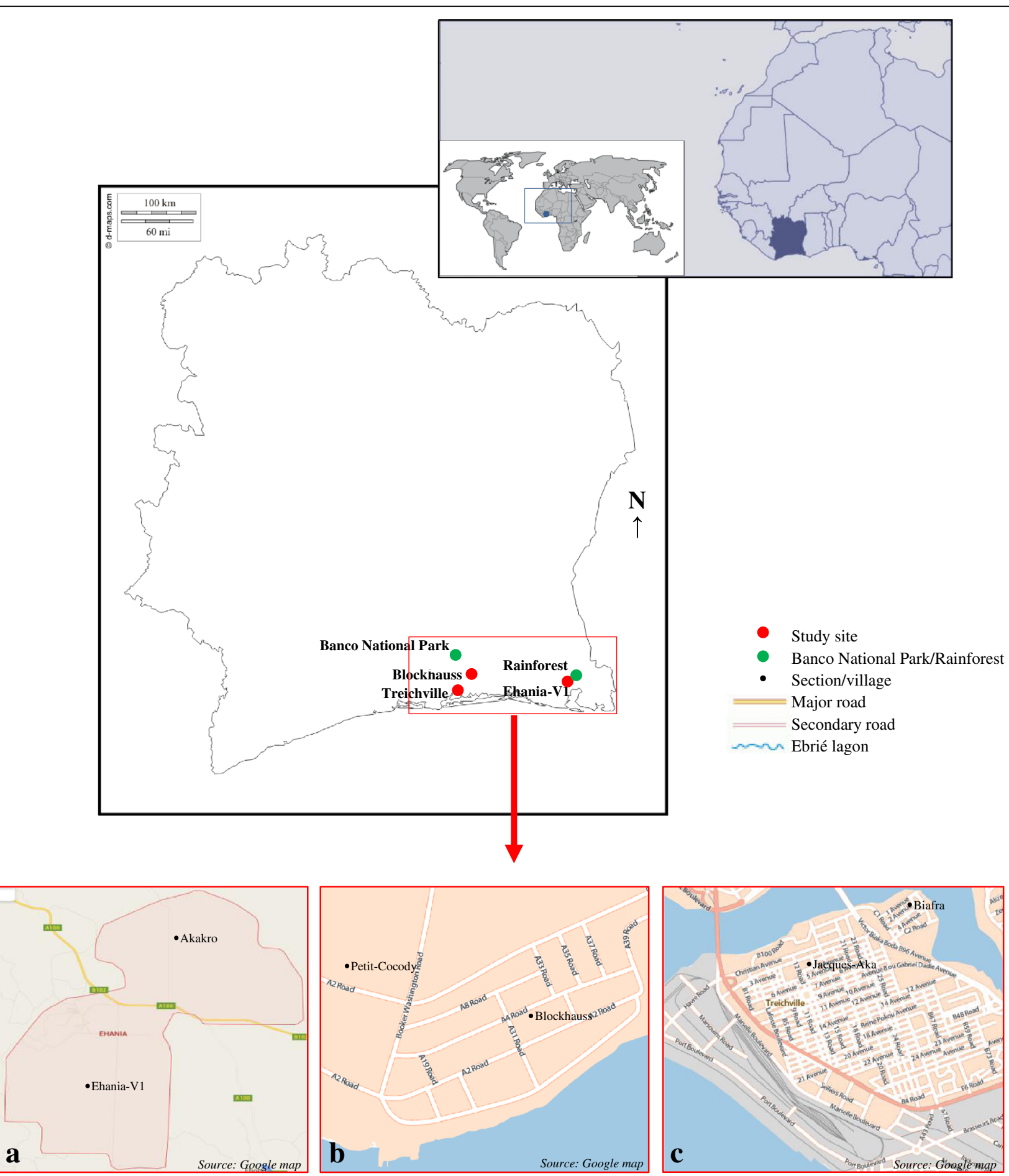

a

Fig. 1 Map of the areas located in southeastern Côte d'Ivoire where the ecological study of Aedes mosquitoes was carried out: a Ehania-V1 (covers the villages of Ehania-V1 and Akakro and represents the rural area without major and secondary paved roads. The site is close to the primary rainforest reserve). b Blockhauss (comprises the villages of Blockhauss and Petit-Cocody and represents the suburban area with only secondary paved roads. It is about $5 \mathrm{~km}$ away from the rainforest of Banco National Park). c Treichville (includes the sections of Jacques-Aka and Biafra and is the urban area with numerous major and secondary paved roads. It is located in the centre of Abidjan and is separated from Blockhauss by Ebrié lagoon) 
50) in the rural, $98.0 \%$ in the suburban and $100 \%$ in the urban areas.

\section{Sample laboratory treatment}

In the field, the paddles, Culex egg rafts and remaining water from the ovitraps were separately stored in plastic boxes and then transported in a cold box to the laboratory. The paddles were dried during a period of 5 days at a temperature of $25 \pm 1{ }^{\circ} \mathrm{C}, \mathrm{RH}$ of $80-90 \%$ and a 12:12 h light:dark photoperiod. They were screened with white, insect-proof, nylon netting to prevent eventual egg laying from other mosquitoes and potential predators. The paddles were then separately immersed in plastic cups $(6 \times 9 \times 15 \mathrm{~cm}) 75 \%$ filled with distilled water for attached egg hatching. The process was repeated three times after flooding of 5 days to maximize egg hatching. Emerging larvae were counted and recorded. As there was no reliable larval identification key, the larvae were reared until adult stage under identical conditions as paddle drying. To avoid overcrowding and limit mortality, at most 20 emerging larvae were placed per $200 \mathrm{ml}$ plastic cup filled to $75 \%$ with distilled water. Each plastic cup was labeled with a unique number of the sample, the study area and the date of collection. Larvae were fed each morning (07:00-08:00 h) with Tetra-Min Baby Fish Food ${ }^{\circ}$. Emerging pupae were transferred to new plastic cups using plastic pipettes for adult emergence. The cups containing the pupae were netted to avoid draining the newly hatched adults. Culex egg rafts were not dried but were stored at $15 \pm 1{ }^{\circ} \mathrm{C}$ to avoid desiccation [36]. In addition, the larvae hatched from Culex egg rafts and the larvae of Aedes, Culex and Eretmapodites found in the collected water from the ovitraps were also separately reared until adult stage, under the same conditions as described above. During rearing, emerging adult Aedes, Culex and Eretmapodites specimens were identified to the species level using morphological criteria [23, 24, 37]. The mosquito individuals were stored at subgenus, species and sex levels and data were recorded in an entomology collection database.

\section{Statistical analysis}

The measures of Aedes species proportions were expressed as the percentage of specimens among Aedes fauna for each study area and analysed using Fisher's exact test to look at the relationship between the species composition and the study area and ecozone, and followed by the Proportion-test. Fisher's exact test was used because expected numbers of specimens were equal or less than five. Aedes species richness was assessed as the number of collected species in each study area and compared using a one-way analysis of variance (ANOVA), followed by Bonferroni's correction. The species diversity and dominance of Aedes spp. were estimated by Shannon-Weaver's index [38] and Simpson's index [39] and analysed by KruskalWallis test because the log-transformed data exhibited significant deviations from normality. The abundance of Aedes spp. and Ae. aegypti was expressed as the mean number of specimens per ovitrap and analysed using repeated measures approaches in a generalized linear mixed model (GLMM) framework in order to take into account the possible interactions between the variables "month", "study site" and "ecozone" [35]. To account for overdispersion due to excessive numbers of zeroes, the data were logtransformed [log (number of specimens + 1)] [36]. The logtransformed data were subjected to GLMM procedures and analysed as follows [35]. We compared the mean numbers of Aedes mosquito specimens per ovitrap between the study areas, the ecozones and the months using mixedeffects regression (xtmixed command), performed the joint tests of the interactions and the main effects of the study sites, the ecozones and months (contrast command) to understand the significant interactions, followed up the simple effects of each study area and ecozone over the months by pairwise comparisons (margins and pwcompare commands) and the post-hoc test of the trends (contrast $p$. operator) and the post-hoc test of the partial interaction (contrast $a$. operator). The mortality of the larvae during rearing was compared using negative binomial error. The extra sub-site, sylvatic zone, was excluded from the analysis when performing the comparisons between the study areas, and only included when the comparisons were conducted among the ecozones in the rural area. A significance level of $5 \%$ was set for statistical testing. All data were analysed using Stata version 14.0 (Stata Corporation; College Station, TX, USA).

\section{Results}

\section{Species composition of emerged adult mosquitoes}

The mortality of the larvae hatched from Aedes spp. eggs during the rearing to adult stage was not statistically significant (all $P>0.05$ ) thus making the comparison of emerged adults possible. Table 1 shows the species composition of adult Aedes spp. emerged from eggs collected from the different study areas. Totals of 2441, 2440 and 3098 adult Aedes spp. emerged from the eggs collected in the rural, suburban and urban areas, respectively. Aedes species belonged to three subgenera (Stegomyia, Aedimorphus and Diceromyia) in the rural areas, two subgenera (Stegomiya and Aedimorphus) in the suburban areas and a single subgenus (Stegomyia) in the urban areas. The species richness of Aedes spp. gradually decreased from the rural (eight species) to the suburban (three species) and urban (one species) areas. Fisher's exact test indicated that Aedes species richness significantly varied from one study area to another (all $P<0.001$ ). Proportion-testing indicated that there was a significant difference in Aedes species 
proportions in the rural $\left(\chi^{2}=9411.15, d f=7, P<0.0001\right)$ and the suburban $\left(\chi^{2}=5052.86, d f=2, P<0.0001\right)$ areas. Aedes aegypti was the predominant species with significantly higher proportions among Aedes fauna collected in the rural $(Z=18.91, P<0.001)$ and suburban areas $(Z=$ 7.83, $P<0.001$ ), and the sole Aedes species in the urban areas. Aedes africanus and Ae. dendrophilus in the rural areas and Ae. vittatus in the suburban areas were found in significantly higher proportions. Aedes metallicus represented more than $1 \%$ of the total Aedes fauna in the rural and the suburban areas whereas Ae. furcifer, Ae. fraseri and Ae. luteocpehalus were collected in lower proportions in the rural areas.

Non-Aedes mosquito species were also sampled in all study areas. Totals of 277, 108 and 67 specimens of Culex spp. were sampled from the rural, suburban and urban areas, respectively. In the rural area, Culex spp. was composed of three species, $C x$. nebulosus $(n=277$; $49.4 \%)$, followed by $C x$. quinquefasciatus (28.2 \%) and Cx. poicilipes (22.4\%). The diversity of Culex spp. then decreased to a single species, $C x$. quinquefasciatus, in the suburban $(n=108)$ and urban $(n=133)$ areas. Eretmapodites spp. was restricted to the rural area and composed of only one species, Er. chrysogaster, with 274 specimens.

\section{Richness, diversity and dominance of Aedes spp.}

Table 2 presents the species richness, diversity and dominance of Aedes spp. in all of the study areas and different ecozones. Aedes spp. species richness was significantly different among the study areas $(F=18.60, d f=2, P=0.0001)$ and ecozones $(F=9.24, d f=6, P<0.0001)$, with higher numbers of species in the rural area and the peridomestic zone of the same area. The species diversity of Aedes spp. was statistically different among the study areas $\left(\chi^{2}=\right.$ 14.00, $d f=2, P=0.0009)$ and ecozones $\left(\chi^{2}=27.65, d f=6\right.$, $P=0.0001)$, with higher values for both diversity indices in the rural area and the sylvatic zone of the rural area. Moreover, Aedes spp. species dominance was significantly different among the study areas $\left(\chi^{2}=13.86, d f=2, P=\right.$ $0.0011)$ and ecozones $\left(\chi^{2}=28.00, d f=6, P=0.0001\right)$, with higher Simpson's index values in the urban area and both peridomestic and domestic zones of the urban area.

\section{Dynamics of Aedes spp. numbers}

The highest mean numbers of emerged adult Aedes spp. were found in the urban setting $(1.97 \pm 0.10$ Aedes/ovitrap/week), followed by the suburban $(1.44 \pm 0.09$ Aedes/ ovitrap/week) and rural ( $0.89 \pm 0.06$ Aedes/ovitrap/week) areas. The mean numbers of emerged adult Aedes spp. were significantly different between the rural and urban areas $(Z=5.01, P<0.001)$. The effects and the interactions among the study areas, the ecozones and months, and the trends of Aedes spp. numbers over the months were statistically significant (Table 3 ).

Table 4 summarises the geographical variation of adult Aedes species collected in each of the three study areas. In the rural areas, specimens of Ae. africanus, Aedes dendrophilus, Aedes metallicus and Aedes fraseri were collected in the domestic zone, while significant numbers of Ae. aegypti were sampled in the sylvatic zone. Emerged adult Aedes spp. mean numbers were significantly higher in the peridomestic zone with $1.36 \pm 0.14$ Aedes/ovitrap/week in the rural (Contrast $=0.50, Z=5.16, P<0.001)$, suburban $(2.10$ \pm 0.15 Aedes/ovitrap/week; Contrast $=-4.89, Z=-4.81, P<$ $0.001)$ and urban $(2.80 \pm 0.21$ Aedes/ovitrap/week; Contrast $=-0.49 ; Z=-4.85, P<0.001)$ areas.

Additional file 1: Table S1 indicates the seasonal variation of emerged adult Aedes spp. in all of the different study areas. Aedes metallicus, Aedes usambara, Ae. fraseri, Ae. luteocephalus and Ae. furcifer were not collected in January 2014 and April 2014. However, Ae. aegypti was sampled in all surveys in each study area. In all of the study areas, higher numbers of emerged adult Aedes spp. were found in July 2013 with $1.47 \pm 0.18$ Aedes/ovitrap/week in the rural, $2.31 \pm 0.29$ Aedes/ovitrap/week in the suburban and $4.06 \pm 0.28$ in the urban areas (Fig. 2). Conversely, the significantly respective lowest numbers of Aedes spp. were recorded in January 2014 with $0.47 \pm$ 0.13 (all $P<0.05$ ), $0.43 \pm 0.17$ (all $P<0.05$ ) and $0.47 \pm$ 0.11 (all $P<0.001$ ) Aedes/ovitrap/week.

\section{Dynamics of Ae. aegypti}

A total of $1754(n=2421 ; 63.3 \pm 1.2 \%)$ adult Ae. aegypti emerged from the eggs collected from the rural areas, $2159(n=2440 ; 85.5 \pm 0.8 \%)$ from the suburban and $3098(n=3098 ; 100 \%)$ from the urban areas (Table 1$)$. The highest mean numbers of Ae. aegypti were found in the urban setting, with $1.97 \pm 0.10$ Ae. aegypti/ovitrap/ week). Considerably lower mean numbers were recorded in the rural and suburban settings, with $0.57 \pm 0.05$ and $1.20 \pm 0.09 \mathrm{Ae}$. aegypti/ovitrap/week, respectively. Aedes aegypti mean numbers were significantly different between the urban and rural $(Z=6.23, P<0.001)$, and the suburban and rural $(Z=2.15, P<0.05)$ areas. The effects of, and interactions among the study areas, ecozones and months, and the trends of Ae. aegypti numbers over the months were statistically significant (Table 3 ).

Figure 3 shows the geographical variations of adult Ae. aegypti mean numbers and frequencies. Significantly higher mean numbers per ovitrap of Ae. aegypti were found in the peridomestic zones with $0.85 \pm 0.12$ Ae. aegypti/ovitrap/week in the rural (Contrast $=0.48$, $Z=5.68, \quad P<0.001) ; 1.64 \pm 0.14 \quad$ Ae. aegypti/ovitrap/ week in the suburban (Contrast $=-0.36, Z=-3.65, P<$ 0.001 ); and $2.80 \pm 0.21 \mathrm{Ae}$. aegypti/ovitrap/week in the urban (Contrast $=-0.49, Z=-5.04, P<0.001$ ) settings. 
Table 1 Species composition of emerged adult Aedes spp. collected in the rural, suburban and urban areas of southeastern Côte d'Ivoire between January 2013 and April 2014

\begin{tabular}{|c|c|c|c|c|c|c|c|c|c|c|c|c|c|c|c|c|}
\hline \multirow[t]{2}{*}{ Subgenus } & \multirow[t]{2}{*}{ Species } & \multicolumn{5}{|l|}{ Rural } & \multicolumn{5}{|c|}{ Suburban } & \multicolumn{5}{|l|}{ Urban } \\
\hline & & Female & Male & Total & $\%$ & $\mathrm{MO} \pm \mathrm{SE}$ & Female & Male & Total & $\%$ & $\mathrm{MO} \pm \mathrm{SE}$ & Female & Male & Total & $\%$ & $\mathrm{MO} \pm \mathrm{SE}$ \\
\hline \multirow[t]{7}{*}{ Aedes (Stegomyia) } & Aedes aegypti & 913 & 841 & 1754 & $63.3^{a}$ & $0.57 \pm 0.05$ & 1124 & 1035 & 2159 & $85.5^{a}$ & $1.20 \pm 0.09$ & 1521 & 1577 & 3098 & 100 & $1.97 \pm 0.10$ \\
\hline & Aedes africanus & 137 & 139 & 276 & $9.4^{b}$ & $0.08 \pm 0.02$ & 0 & 0 & 0 & 0 & 0 & 0 & 0 & 0 & 0 & 0 \\
\hline & Aedes dendrophilus & 122 & 139 & 261 & $8.0^{\mathrm{b}}$ & $0.07 \pm 0.02$ & 0 & 0 & 0 & 0 & 0 & 0 & 0 & 0 & 0 & 0 \\
\hline & Aedes metallicus & 22 & 14 & 36 & $1.3^{c}$ & $0.01 \pm 0.01$ & 20 & 12 & 32 & $1.2^{c}$ & $0.01 \pm 0.01$ & 0 & 0 & 0 & 0 & 0 \\
\hline & Aedes usambara & 20 & 12 & 32 & $0.5^{c}$ & $0.01 \pm 0.00$ & 0 & 0 & 0 & 0 & 0 & 0 & 0 & 0 & 0 & 0 \\
\hline & Aedes fraseri & 6 & 11 & 17 & $0.3^{c}$ & $0.01 \pm 0.00$ & 0 & 0 & 0 & 0 & 0 & 0 & 0 & 0 & 0 & 0 \\
\hline & Aedes luteocephalus & 8 & 3 & 11 & $0.3^{c}$ & $0.00 \pm 0.00$ & 0 & 0 & 0 & 0 & 0 & 0 & 0 & 0 & 0 & 0 \\
\hline Aedes (Aedimorphus) & Aedes vittatus & 0 & 0 & 0 & 0 & 0 & 130 & 119 & 249 & $6.5^{\mathrm{b}}$ & $0.09 \pm 0.02$ & 0 & 0 & 0 & 0 & 0 \\
\hline Aedes (Diceromyia) & Aedes furcifer & 20 & 14 & 34 & $0.7^{c}$ & $0.01 \pm 0.01$ & 0 & 0 & 0 & 0 & 0 & 0 & 0 & 0 & 0 & 0 \\
\hline \multirow[t]{2}{*}{ Total } & Abundance & 1248 & 1173 & 2421 & 100 & $0.89 \pm 0.06$ & 1274 & 1166 & 2440 & 100 & $1.44 \pm 0.09$ & 1521 & 1577 & 3098 & 100 & $1.97 \pm 0.10$ \\
\hline & Richness (no. of spp.) & \multicolumn{5}{|l|}{8} & \multicolumn{5}{|l|}{3} & \multicolumn{5}{|l|}{1} \\
\hline
\end{tabular}

Letters indicate the results of the Proportion-test. Groups that do not share the same letter for the same study area are significantly different $(P<0.05)$

Abbreviations: $M O$, mean number per ovitrap; $S E$, standard error of the mean number per ovitrap 
Table 2 Species richness, diversity and dominance of Aedes spp. in the rural, suburban and urban areas and ecozones in southeastern Côte d'Ivoire

\begin{tabular}{llll}
\hline Area/ Ecozone & Richness & $\begin{array}{l}\text { Shannon's } \\
\text { diversity index }\end{array}$ & $\begin{array}{l}\text { Simpson's } \\
\text { dominance index }\end{array}$ \\
\hline Area & $8^{\mathrm{a}}$ & $1.39^{\mathrm{a}}$ & $0.55^{\mathrm{b}}$ \\
$\begin{array}{l}\text { Rural } \\
\text { Suburban }\end{array}$ & $3^{\mathrm{b}}$ & $0.57^{\mathrm{a}, \mathrm{b}}$ & $0.79^{\mathrm{a}, \mathrm{b}}$ \\
Urban & $1^{\mathrm{b}}$ & $0^{\mathrm{b}}$ & $1^{\mathrm{a}}$ \\
Ecozone & & & \\
Sylvatic $^{1}$ & $5^{\mathrm{a}, \mathrm{b}}$ & $1.90^{\mathrm{a}}$ & $0.28^{\mathrm{c}}$ \\
Peridomestic $^{1}$ & $7^{\mathrm{a}, \mathrm{b}}$ & $1.23^{\mathrm{a}, \mathrm{b}}$ & $0.58^{\mathrm{b}, \mathrm{c}}$ \\
Domestic $^{1}$ & $5^{\mathrm{b}, \mathrm{c}}$ & $0.75^{\mathrm{a}, \mathrm{b}, \mathrm{c}}$ & $0.77^{\mathrm{a}, \mathrm{b}, \mathrm{c}}$ \\
Peridomestic $^{2}$ & $3^{\mathrm{b}, \mathrm{c}}$ & $0.67^{\mathrm{a}, \mathrm{b}, \mathrm{c}}$ & $0.74^{\mathrm{a}, \mathrm{b}, \mathrm{c}}$ \\
Domestic $^{2}$ & $3^{\mathrm{b}, \mathrm{c}}$ & $0.35^{\mathrm{a}, \mathrm{b}, \mathrm{c}}$ & $0.89^{\mathrm{a}, \mathrm{b}, \mathrm{c}}$ \\
Peridomestic $^{3}$ & $1^{\mathrm{c}}$ & $0^{\mathrm{c}}$ & $1^{\mathrm{a}}$ \\
Domestic $^{3}$ & $1^{\mathrm{c}}$ & $0^{\mathrm{c}}$ & $1^{\mathrm{a}}$ \\
\hline
\end{tabular}

Letters indicate the results of one-way ANOVA test followed by Bonferroni correction (richness) and Kruskal-Wallis test (Shannon diversity index, Simpson dominance index). Groups that do not share the same letter are significantly different $(P<0.05)$

${ }^{1} E$ Ecozone in the rural area

${ }^{2} E c o z o n e$ in the suburban area

${ }^{3}$ Ecozone in the urban area

Aedes aegypti was collected in all of the ecozones of each study area. Its frequencies gradually increased from the sylvatic zone of the rural area $(n=395$; $33.4 \%)$ to the domestic zone of the urban area $(n=$ $1160 ; 100 \%)(Z=31.43, P<0.001)$.

Figure 4 shows the monthly variations of emerged adult Ae aegypti mean numbers in relation to the rainfall. Emerged adult Ae aegypti mean numbers significantly varied as a function of rainfall fluctuation in all study areas. The highest mean numbers were found during the rainy season in July 2013 with $0.96 \pm 0.14$ Ae. aegypti/ovitrap/week in the rural and $4.06 \pm 0.28 \mathrm{Ae}$. aegypti/ovitrap/week in the urban areas, and in October 2013 with $1.65 \pm 0.25 \mathrm{Ae}$. aegypti/ovitrap/week in the suburban areas. In urban areas, Ae. aegypti mean numbers dramatically declined in January $2014(0.47 \pm 0.11$ Ae. aegypti/ovitrap/week) compared to July 2013 (Contrast $=-1.25, Z=-7.88, P<0.001)$. In the same study area, Ae. aegypti numbers were significantly higher in January 2013 (3.08 \pm 0.11 Ae. aegypti/ovitrap/week) compared to January 2014 (Contrast $=-1.02, Z=-6.57, P<$ $0.001)$.

\section{Discussion}

To our knowledge, this is the first study exploring oviposition ecology of Aedes mosquitoes in variously urbanized settings of Côte d'Ivoire. Importantly, several species of Aedes were involved in previous dengue and yellow fever outbreaks in Côte d'Ivoire [18-22]. The outbreaks might be explained by the paucity of vector control strategies. A deeper understanding of the modifications induced by urbanization in the ecology of Aedes mosquitoes is crucial. Our data suggest that Aedes oviposition ecology and species composition, and Ae. aegypti dynamics differ from rural to suburban and urban areas in southeastern Côte d'Ivoire.

Our data highlighted that the mean numbers of emerged adult Aedes spp. increase from rural to urban areas. An increase in Aedes species prevalence and abundance by urbanization was indicated by Li et al. [2]. This phenomenon is probably due to elevated numbers of Aedes breeding sites such as tyres, discarded cans or water storage containers, provided by urbanizing environment [2]. In addition, an urbanized environment accelerates Aedes mosquito development and survivorship [2]. By increasing Aedes spp. abundance, urbanization could potentially aggravate epidemic risk factors for arbovirus.

Our results showed that urbanization alters Aedes mosquito species composition towards dominance of $A e$. aegypti in the urban areas, while rural and suburban areas favour other wild Aedes species, including Ae. vittatus, Ae. dendrophilus, Ae. africanus, Ae. luteocephalus, Ae. furcifer, Ae. metallicus, Ae. usambara and Ae. fraseri. Aedes aegypti eggs are expected to be more desiccation-resistant [23, 24]; this might raise their ability to survive in a deforested environment such as the urban areas exposed to direct sunlight and thus increase the species geographical invasion. Conversely, the wild Aedes species collected only in the rural and suburban settings probably originated from a natural environment such as the preserved rainforest and the Banco National Park forest, respectively. The disappearance of wild Aedes species in the urban settings might be explained by the destruction of the natural environment for building houses and other infrastructure. The removal of vegetation due to house constructions and other infrastructure developments results in direct exposure of Aedes spp. breeding sites to solar radiation. The wild Aedes species eggs from rural settings could be protected against solar radiation by rainforest canopy [40] since they are laid in tree holes [41] and bamboo internodes [42] filled by rainwater and maintained under low temperature. It is conceivable that wild Aedes species that lay more fragile and desiccation-sensitive eggs remain confined to the rural areas, mainly in the rainy forest [23, 24]. Additional field manipulations and experiments under controlled laboratory conditions testing the different Aedes species egg desiccation-resistance levels may be useful to better understand the segregation among the species and the population growth rates. Indeed, the forest-dwelling Aedes species that are still present in the rural areas may play a key role as bridge vectors between the sylvatic cycles of dengue, yellow fever and other viruses among non-human primates 
Table 3 Effects, interactions and trends of Aedes spp. and Ae. aegypti numbers in the rural, suburban and urban areas in southeastern Côte d'Ivoire. The results are the outputs of the generalized linear mixed model (GLMM) procedures. The extra sub-site, sylvatic zone, was excluded from the data

\begin{tabular}{|c|c|c|c|c|c|c|c|}
\hline & & \multicolumn{3}{|c|}{ Aedes spp. } & \multicolumn{3}{|c|}{ Aedes aegypti } \\
\hline & & $x^{2}$ & $d f$ & P & $x^{2}$ & $d f$ & P \\
\hline \multicolumn{8}{|c|}{ 1. Main effect \& interaction } \\
\hline \multicolumn{8}{|l|}{ 1.1. Main effect } \\
\hline \multicolumn{2}{|l|}{ Study area } & 20.16 & 2 & $<0.00001^{*}$ & 50.37 & 2 & $<0.00001^{*}$ \\
\hline \multicolumn{2}{|l|}{ Ecozone } & 43.76 & 1 & $<0.00001^{*}$ & 26.32 & 1 & $<0.00001^{*}$ \\
\hline \multicolumn{2}{|l|}{ Month } & 112.78 & 5 & $<0.00001^{*}$ & 82.67 & 5 & $<0.00001^{*}$ \\
\hline \multicolumn{8}{|l|}{ 1.2. Interaction } \\
\hline \multicolumn{2}{|c|}{ Study area $\times$ ecozone } & 7.09 & 2 & $0.0288^{*}$ & 13.25 & 2 & $0.0013^{*}$ \\
\hline \multicolumn{2}{|c|}{ Study area $\times$ month } & 15.90 & 10 & 0.1027 & 26.52 & 10 & $0.0031^{*}$ \\
\hline \multicolumn{2}{|c|}{ Ecozone $\times$ month } & 12.26 & 5 & $0.0314^{*}$ & 8.69 & 5 & 0.1221 \\
\hline \multicolumn{2}{|c|}{ Study area $\times$ ecozone $\times$ month } & 14.96 & 10 & 0.1335 & 8.29 & 10 & 0.6003 \\
\hline \multicolumn{8}{|c|}{ 2. Post-hoc test of trends } \\
\hline 2.1. Study area & Trend & & & & & & \\
\hline \multirow[t]{5}{*}{ Rural } & Linear & 2.55 & 1 & 0.1102 & 0.43 & 1 & 0.5109 \\
\hline & Quadratic & 1.19 & 1 & 0.2752 & 2.81 & 1 & 0.0935 \\
\hline & Cubic & 9.36 & 1 & $0.0022^{*}$ & 5.20 & 1 & $0.0225^{*}$ \\
\hline & Quartic & 6.08 & 1 & $0.0136^{*}$ & 4.70 & 1 & $0.0302^{*}$ \\
\hline & Quintic & 1.03 & 1 & 0.3099 & 0.06 & 1 & 0.7999 \\
\hline \multirow[t]{5}{*}{ Suburban } & Linear & 7.31 & 1 & $0.0068^{*}$ & 4.86 & 1 & 0.275 \\
\hline & Quadratic & 2.91 & 1 & 0.0880 & 0.92 & 1 & 0.3377 \\
\hline & Cubic & 10.09 & 1 & $0.0015^{*}$ & 5.67 & 1 & $0.0173^{*}$ \\
\hline & Quartic & 16.54 & 1 & $<0.00001^{*}$ & 7.05 & 1 & $0.0079^{*}$ \\
\hline & Quintic & 0.46 & 1 & 0.4969 & 3.58 & 1 & 0.0584 \\
\hline \multirow[t]{5}{*}{ Urban } & Linear & 26.45 & 1 & $<0.00001^{*}$ & 27.16 & 1 & $<0.00001^{*}$ \\
\hline & Quadratic & 0.02 & 1 & 0.8767 & 0.02 & 1 & 0.8798 \\
\hline & Cubic & 15.22 & 1 & $0.0001^{*}$ & 15.64 & 1 & $0.0001^{*}$ \\
\hline & Quartic & 28.58 & 1 & $<0.00001^{*}$ & 29.42 & 1 & $<0.00001^{*}$ \\
\hline & Quintic & 2.67 & 1 & 0.1020 & 2.74 & 1 & 0.0981 \\
\hline \multicolumn{2}{|l|}{ Joint } & 128.68 & 15 & $<0.00001^{*}$ & 109.47 & 1 & $<0.00001^{*}$ \\
\hline \multicolumn{8}{|l|}{ 2.2. Ecozone } \\
\hline \multirow[t]{5}{*}{ Peridomestic } & Linear & 23.32 & 1 & $<0.00001^{*}$ & 21.11 & 1 & $<0.00001^{*}$ \\
\hline & Quadratic & 1.24 & 1 & 0.2658 & 0.53 & 1 & 0.4679 \\
\hline & Cubic & 17.00 & 1 & $<0.00001^{*}$ & 9.87 & 1 & $0.0017^{*}$ \\
\hline & Quartic & 47.09 & 1 & $<0.00001^{*}$ & 31.48 & 1 & $<0.00001^{*}$ \\
\hline & Quintic & 2.87 & 1 & 0.0900 & 0.21 & 1 & 0.6487 \\
\hline \multirow[t]{5}{*}{ Domestic } & Linear & 8.28 & 1 & $0.0040^{*}$ & 3.96 & 1 & $0.0465^{*}$ \\
\hline & Quadratic & 1.08 & 1 & 0.2978 & 1.71 & 1 & 0.1915 \\
\hline & Cubic & 17.26 & 1 & $<0.00001^{*}$ & 15.23 & 1 & $0.0001^{*}$ \\
\hline & Quartic & 7.85 & 1 & $0.0051^{*}$ & 7.46 & 1 & $0.0063^{*}$ \\
\hline & Quintic & 0.02 & 1 & 0.8846 & 0.23 & 1 & 0.6330 \\
\hline \multicolumn{2}{|l|}{ Joint } & 122.97 & 10 & $<0.00001^{*}$ & 90.52 & 10 & $<0.00001^{*}$ \\
\hline
\end{tabular}


Table 4 Geographical variations in the number of emerged adult species of Aedes spp. in the rural, suburban and urban areas in southeastern Côte d'Ivoire

\begin{tabular}{|c|c|c|c|c|c|c|c|c|c|c|c|c|c|c|}
\hline \multirow[t]{3}{*}{ Species } & \multicolumn{6}{|c|}{ Rural } & \multicolumn{4}{|c|}{ Suburban } & \multicolumn{4}{|c|}{ Urban } \\
\hline & \multicolumn{2}{|c|}{ Sylvatic zone } & \multicolumn{2}{|c|}{$\begin{array}{l}\text { Peridomestic } \\
\text { zone }\end{array}$} & \multicolumn{2}{|c|}{ Domestic zone } & \multicolumn{2}{|c|}{$\begin{array}{l}\text { Peridomestic } \\
\text { zone }\end{array}$} & \multicolumn{2}{|c|}{ Domestic zone } & \multicolumn{2}{|c|}{$\begin{array}{l}\text { Peridomestic } \\
\text { zone }\end{array}$} & \multicolumn{2}{|c|}{ Domestic zone } \\
\hline & $n$ & $\mathrm{MO} \pm \mathrm{SE}$ & $n$ & $\mathrm{MO} \pm \mathrm{SE}$ & $n$ & $\mathrm{MO} \pm \mathrm{SE}$ & $n$ & $\mathrm{MO} \pm \mathrm{SE}$ & $n$ & $\mathrm{MO} \pm \mathrm{SE}$ & $n$ & $\mathrm{MO} \pm \mathrm{SE}$ & $n$ & $\mathrm{MO} \pm \mathrm{SE}$ \\
\hline Aedes aegypti & 132 & $0.15 \pm 0.04$ & 901 & $0,85 \pm 0.12$ & 721 & $0.84 \pm 0.10$ & 1353 & $1.64 \pm 0.14$ & 806 & $0.86 \pm 0.11$ & 1938 & $2.80 \pm 0.21$ & 1160 & $1.34 \pm 0.16$ \\
\hline Aedes africanus & 106 & $0.10 \pm 0.03$ & 161 & $0.14 \pm 0.04$ & 9 & $0.01 \pm 0.01$ & 0 & 0 & 0 & 0 & 0 & 0 & 0 & 0 \\
\hline Aedes dendrophilus & 121 & $0.11 \pm 0.03$ & 91 & $0.07 \pm 0.03$ & 49 & $0.05 \pm 0.02$ & 0 & 0 & 0 & 0 & 0 & 0 & 0 & 0 \\
\hline Aedes metallicus & 2 & $0.00 \pm 0.00$ & 7 & $0.01 \pm 0.00$ & 27 & $0.02 \pm 0.01$ & 28 & $0.02 \pm 0.01$ & 4 & $0.01 \pm 0.01$ & 0 & 0 & 0 & 0 \\
\hline Aedes usambara & 0 & 0 & 32 & $0.02 \pm 0.02$ & 0 & 0 & 0 & 0 & 0 & 0 & 0 & 0 & 0 & 0 \\
\hline Aedes fraseri & 0 & 0 & 1 & $0.00 \pm 0.00$ & 16 & $0.01 \pm 0.01$ & 0 & 0 & 0 & 0 & 0 & 0 & 0 & 0 \\
\hline Aedes luteocephalus & 0 & 0 & 11 & $0.01 \pm 0.01$ & 0 & 0 & 0 & 0 & 0 & 0 & 0 & 0 & 0 & 0 \\
\hline Aedes vittatus & 0 & 0 & 0 & 0 & 0 & 0 & 201 & $0.15 \pm 0.05$ & 48 & $0.30 \pm 0.00$ & 0 & 0 & 0 & 0 \\
\hline Aedes furcifer & 34 & $0.02 \pm 0.02$ & 0 & 0 & 0 & 0 & 0 & 0 & 0 & 0 & 0 & 0 & 0 & 0 \\
\hline Abundance & 395 & $0.44 \pm 0.03$ & 1204 & $1.36 \pm 0.14$ & 822 & $1.01 \pm 0.01$ & 1582 & $2.10 \pm 0.15$ & 858 & $0.94 \pm 0.11$ & 1938 & $2.80 \pm 0.21$ & 1160 & $1.34 \pm 0.16$ \\
\hline
\end{tabular}

Abbreviations: $n$, total number of specimens; $M O$, mean number of specimens per ovitrap per week; $S E$, standard error of the mean

and humans [17]. The vector role of these Aedes species is subtle and difficult to trace, and often remains undetected because there are no traditional epidemiological risk indicators such as the house index, container index or Breteau index [43]. However, the exclusive existence of predators such as Er. chrysogaster in the rural areas might influence the abundance of Aedes species [27, 42]. Er. chrysogaster is also suspected to transmit arboviruses in tropical Africa [23]. In summary, the segregation induced by urbanization in Aedes species diversity is consistent with the known arbovirus transmission cycles in tropical Africa [17] and merits further consideration for dengue and yellow fever surveillance.

Our results suggested that the geographical and seasonal variations of Aedes spp. are associated with urbanized settings. The preference of Aedes spp. to lay eggs in the peridomestic vicinity confirms previous findings from urban areas in Brazil [44] and Vietnam [45]. Peridomestic premises are in close proximity to human residencies, and hence the principal blood-meal sources of adult Aedes mosquitoes. Furthermore, they also provide ideal ecosystems such as dense vegetation favourable for Aedes spp. refugia [46] and natural breeding sites such as tree holes [39, 42, 47] and artificial containers as discarded cans and old vehicle tyres $[48,49]$. Regarding the seasonal variation, Aedes spp. mean numbers were strongly associated with rainfall patterns, history, variability and intensity. The fluctuations in Aedes spp. counts could be influenced by seasonal flooding-drying cycles as reported in Côte d'Ivoire [18] and Brazil [44]. Aedes spp. eggs probably enter into a dormant

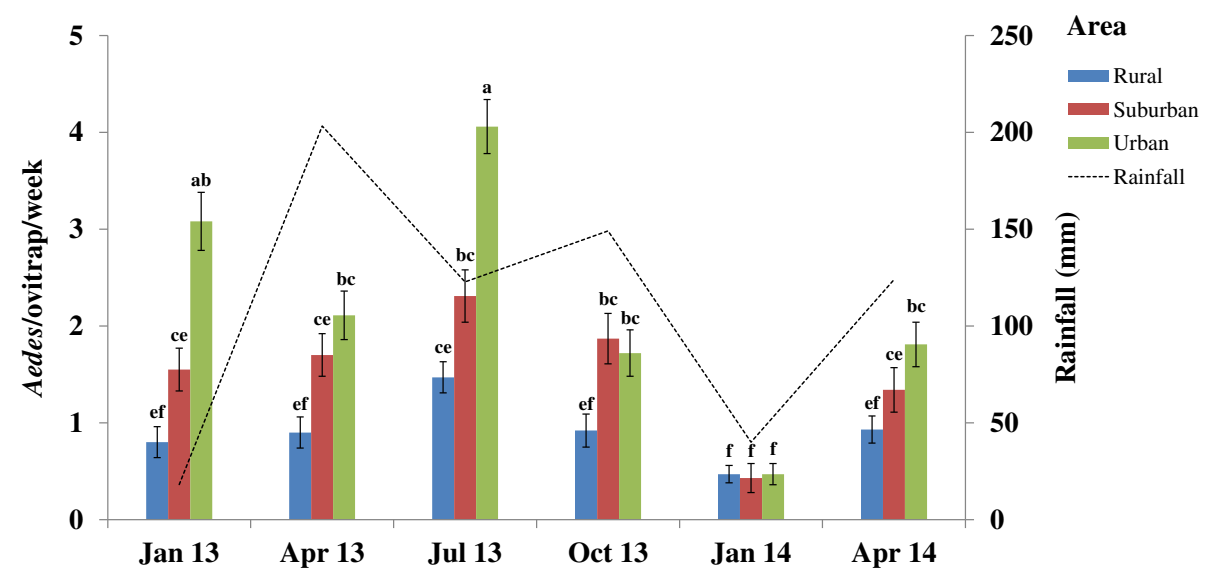

Fig. 2 Monthly variations in mean numbers of emerged adult Aedes spp. as a function of the rainfall period. Rainfall was unexpectedly high in April 2013. The highest precipitations (374 mm) occurred in June 2013. Error bars show the standard error (SE) of the mean number of Aedes spp. per ovitrap. The letters indicate the results of the data analysed as repeated measures by generalized linear mixed model (GLMM) procedures. Groups that do not share a same letter are significantly different $(P<0.05)$ 


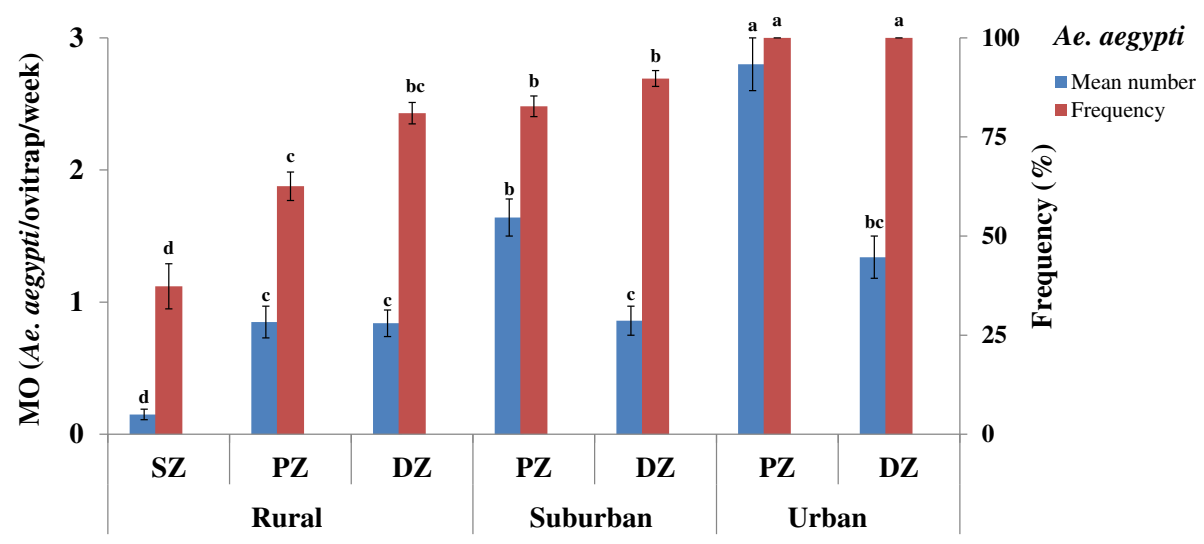

Fig. 3 Geographical variations in mean numbers and frequencies of emerged adult Ae. aegypti. Error bars show the standard error (SE) of the mean number per ovitrap (MO) and the frequency. The letters indicate the results of the data analysed as repeated measures by Generalized Linear Mixed Model (GLMM) procedures for the mean number and Proportion-test for the frequency. Groups that do not share a same letter are significantly different $(P<0.05)$. Abbreviations: MO, mean numbers per ovitrap; SZ, sylvatic zone; $\mathrm{PZ}$, peridomestic zone; DZ, domestic zone

stage to withstand desiccation periods during the dry season, while precipitations might flood the breeding sites and increase the abundance of Aedes spp. [50]. However, the sudden decline of Aedes spp. numbers in October 2013 in the urban setting might be due to heavy precipitations and exacerbated flushing of their eggs because of the lack of protective vegetation in the built-up environment [51].

Finally, our findings revealed that Ae. aegypti is the most common species along the increasing urbanization gradient and the unique Aedes species in urban settings, thus suggesting particular attention on its egg laying patterns and population dynamics. Aedes aegypti is an urban species that preferentially feeds on humans [52] and is well adapted to live in close proximity to human habitats [53]. Such highly anthropophilic behaviour may enhance human-to-human transmission of arboviruses and trigger dengue and yellow fever outbreaks. The dominance of Ae. aegypti in still urbanizing and already urbanized areas of Africa is well documented [8, 9, 18] and is possibly due to its plastic oviposition behaviour allowing the colonization of natural and artificial environments $[9,42]$. Otherwise, the rising occurrence of Ae. aegypti was also coupled with the increasing presence of another urban, anthropophilic and sympatric species, Cx. quinquefasciatus [54-56] and the lack of predators such as Er. chrysogaster [27] in the urban area. In contrast, the specimens of Ae. aegypti unexpectedly collected in the sylvatic zone are, perhaps, members of the Aedes aegypti formosus, the ancestral progenitor of Aedes aegypti aegypti and the only sylvan form known in West Africa [30, 31]. Aedes aegypti formosus has no white scales on the first abdominal tergite and a dark or

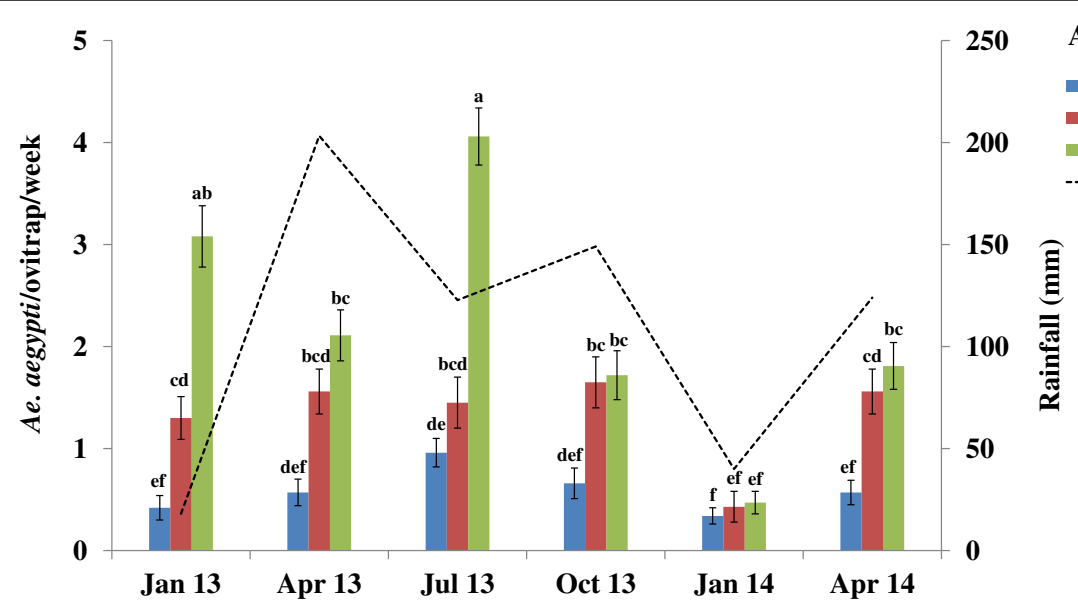

Fig. 4 Monthly variations in mean numbers of emerged adult Ae. aegypti as a function of the rainfall period. Rainfall was unexpectedly high in April 2013. The highest precipitations (374 mm) occurred in June 2013. Error bars show the standard error (SE) of the mean number of Ae. aegypti per ovitrap. The letters indicate the results of the data analysed as repeated measures by generalized linear mixed model (GLMM) procedures. Groups that do not share a same letter are significantly different $(P<0.05)$ 
black cuticle. This subspecies is exophilic, preferentially feeds on wild animals and breeds in natural containers such as tree holes [32, 57, 58], whereas, Ae. aegypti aegypti has scales on the first abdominal tergite and a lightly tanned cuticle and tends to be endo- and anthropophilic and breed in man-made containers [31]. However, contrary to East Africa [29, 30, 57], the scaling and behavioural patterns do not match with the discrete genetic differences in allozymes and microsatellites for Ae. aegypti collected in West Africa [13, 31, 33, 40, 59]. This results in confusion over morphological distinction between the two forms [13]. Due to these ambiguities, we were not able to confirm which Ae. aegypti form was represented among the sylvan specimens collected in the rural area. Above all, the urban and sylvan forms of Ae. aegypti are both competent arbovirus vectors in West Africa [13].

Urbanization continues at a rapid pace in Côte d'Ivoire, particularly in the southeastern part resulting in drastic segregation among Aedes species by favouring Ae. aegypti and restricting wild Aedes species to rural areas. These trends were paralleled by recurrent resurgences of yellow fever and dengue in recent years. However, yellow fever is historically well known as a key factor having forced the transfer of the colonial capital of Côte d'Ivoire from Grand-Bassam to Abidjan in 1899 [60]. Despite this historical and present background, the resurgence of yellow fever and dengue outbreaks is not resolved and their sporadic occurrence creates major public health concerns [60]. Between 2001 and 2007, 1468 suspected, 41 confirmed and 26 fatal cases of yellow fever were reported. During the period of 2007-2001, 111 suspected with 31 confirmed and 43 deadly cases of yellow fever were notified. The incidence of yellow fever gradually increased and peaked in 2011 with 79 cases and 35 deaths. In 2008, nine cases of yellow fever and two cases of dengue DENV-3 were recorded. In 2010, 13 confirmed and two fatal cases of yellow fever, and one deadly case of DENV-1 were reported. The strengthened warning systems and the operated vector control are usually performed in urban areas, mainly in Abidjan. Our study suggests that while vector control should focus on urban areas, rural areas are important as they may serve as transition zones for (re-)introduction of arboviral diseases through sylvatic bridge vectors. Because rural areas host various wild vectors, they act as a potential reservoir and originator of arboviruses from which urban areas are (re-)infected. Therefore, rural areas also need to be considered when elaborating and applying arbovirus vector surveillance and control strategies. Aedes species control strategies could apply the lethal ovitrap [61] and autocidal [62] gravid ovitrap-based on mass trapping method.

\section{Conclusions}

In arbovirus foci of the southeastern Côte d'Ivoire, urbanized environment correlates with a substantially higher abundance in Aedes species and a regression of the Aedes wild species towards a unique presence of Ae. aegypti. Aedes aegypti is expected to drive arbovirus transmission in the urban areas, while other species probably serve as potential bridge vectors between sylvatic and urban cycles of human arboviral infections in the rural areas. Our findings provide valuable information on Aedes spp. ecology patterns in variously urbanized settings and therefore suggest that the rural areas also need to be considered when implementing arbovirus vector surveillance and control strategies.

\section{Additional file}

Additional file 1: Table S1. Seasonal variations in the number of emerged adult species of Aedes spp. in the rural, suburban and urban areas in southeastern Côte d'Ivoire. (DOCX 20 kb)

\section{Abbreviations}

DZ: Domestic zone; GLMM: Generalized linear mixed model; MO: Mean number per ovitrap; PZ: Peridomestic zone; SZ: Sylvatic zone

\section{Acknowledgements}

The authors are grateful to the Centre Suisse de Recherches Scientifiques en Côte d'Ivoire, Abidjan, Côte d'Ivoire, which funded the study and supported its execution. The authors would also like to extend their thanks to PALMCI staff, health authorities, local authorities and residents in the study areas and the mosquito collection teams.

\section{Funding}

The study was funded and its execution was supported by the Centre Suisse de Recherches Scientifiques en Côte d'Ivoire, Abidjan, Côte d'Ivoire.

\section{Availability of data and material}

The datasets supporting the conclusions of this article are included within the article and its additional file.

\section{Authors' contributions}

$J B Z Z, J U, M A A$ and BGK conceived and designed the surveys. JBZZ, MAA, YT and BGK performed the surveys. JBZZ and JU analysed the data. JU, PM, DM, $Y T$ and BGK contributed to the provision of materials, analysis and tools. JBZZ, JU, PM, DM and BGK wrote the paper. All authors read and approved the final manuscript.

\section{Authors' information}

JBZZ, MSc, Medical entomology, PhD student at University of Basel, Basel, Switzerland and researcher at Centre Suisse de Recherches Scientifiques en Côte d'Ivoire, Abidjan, Côte d'Ivoire; JU, PhD, Epidemiology; Director of Swiss Tropical and Public Health Institute and professor at University of Basel, Basel, Switzerland. MAA, PhD, Medical entomology, Professor at Université Félix Houphouët-Boigny, Abidjan, Côte d'Ivoire. PM, PhD, head of Vector Control Group at Swiss Tropical and Public Health Institute, Basel, Switzerland. DM, MSc, Medical entomology, Manager of Innovative Vector Control Consortium, Liverpool School of Tropical Medicine, Liverpool, United Kingdom. YT, PhD, president of Université Nangui-Abrogoua, Abidjan, Côte d'Ivoire and professor at Université Félix Houphouët-Boigny, Abidjan, Côte d'Ivoire. BGK, PhD, Medical entomology, Professor at Université NanguiAbrogoua, Abidjan, Côte d'Ivoire and manager of Centre for Neglected Tropical Diseases, Liverpool School of Tropical Medicine, Liverpool, United Kingdom.

Competing interests

The authors declare that they have no competing interests.

Consent for publication

Not applicable. 


\section{Ethics approval and consent to participate}

The study protocol received approval from the local health and administrative authorities. In addition, all entomological surveys and sample collections carried out on private lands or private residential areas were done with the permission and written informed consent of the owners or residents. These studies did not involve endangered or protected species.

\section{Author details}

'Unité de Formation et de Recherche Biosciences, Université Félix Houphouët-Boigny, Abidjan, Côte d'Ivoire. ${ }^{2}$ Centre Suisse de Recherches Scientifiques en Côte d'Ivoire, Abidjan, Côte d'Ivoire. ${ }^{3}$ Swiss Tropical and Public Health Institute, Basel, Switzerland. ${ }^{4}$ University of Basel, Basel, Switzerland. Innovative Vector Control Consortium, Liverpool School of Tropical Medicine, Liverpool, UK. ${ }^{6}$ Université Nangui-Abrogoua, Abidjan, Côte d'Ivoire. ${ }^{7}$ Filariasis Programme Support Unit from Liverpool School of Tropical Medicine, Liverpool, UK.

Received: 8 January 2016 Accepted: 29 August 2016

Published online: 29 September 2016

\section{References}

1. Gubler DJ. Dengue, urbanization and globalization: the unholy trinity of the $21^{\text {st }}$ century. Trop Med Health. 2011;39:3-11.

2. Li Y, Kamara F, Zhou G, Puthiyakunnon, Li C, Liu Y, et al. Urbanization increases Aedes albopictus larval habitats and accelerates mosquito development and survivorship. PLoS Negl Trop Dis. 2014;8:e3301.

3. Murray CJL, Vos T, Lozano R, Naghavi M, Flaxman AD, Michaud C, et al. Disability-adjusted life years (DALYs) for 291 diseases and injuries in 21 regions, 1990-2010: a systematic analysis for the Global Burden of Disease study 2010. Lancet. 2012;380:2197-223.

4. Gubler DJ. The changing epidemiology of yellow fever and dengue, 1900 to 2003: full circle? Comp Immunol Microbiol Infect Dis. 2004;27:319-30.

5. Bhatt S, Gething PW, Brady OJ, Messina JP, Farlow AW, Moyes CL, et al. The global distribution and burden of dengue. Nature. 2013;496:504-7.

6. Messina JP, Brady OJ, Scott TW, Zou C, Pigott DM, Duada KA, et al. Global spread of dengue virus types mapping the 70 year history. Trends Microbiol. 2014:22:138-46.

7. Brady OJ, Gething PW, Bath S, Messina JP, Brownstein JS, Hoen AG, et al. Refining the global spatial limits of dengue virus transmission by evidencebased consensus. PLoS Negl Trop Dis. 2012;6:e1760.

8. Were F. The dengue situation in Africa. Paediatr Int Child Health. 2012;32:18-21.

9. WHO. Yellow fever. Rapid field entomological assessment during yellow fever outbreaks in Africa. Methodological field approaches for scientists with a basic background in entomology. Australia: Biotext Pty Ltd; 2014.

10. Diallo D, Chen R, Diagne CT, Ba Y, Dia I, Sall AA, et al. Blood-feeding patterns of sylvatic arbovirus vectors in southeastern Senegal. Trans R Soc Trop Med Hyg. 2013;107:200-3.

11. Talla C, Diallo D, Dia I, Ba Y, Ndione J-A, Sall AA, et al. Statistical modeling of the abundance of vectors of West Africa Rift valley fever in Barkédji, Sénégal. PLoS One. 2014;9:e114047.

12. Althouse BM, Hanley M, Diallo M, Sall AA, Ba Y, Faye O, et al. Impact of climate and mosquito vector abundance on sylvatic arbovirus circulation dynamics in Senegal. Am J Trop Med Hyg. 2015;92:88-97.

13. Dickson LB, Sanchez-Vargas I, Sylla M, Fleming K, Black IV WC. Vector competence in western African Aedes aegypti is flavivirus species and genotype dependent. PLoS Negl Trop Dis. 2014;8:e3153.

14. Ridde V, Carabali M, Ly A, Druetz T, Kouanda S, Bonnet E, et al. The need for more research and public health interventions on dengue fever in Burkina Faso. PLoS Negl Trop Dis. 2014;8:e2859.

15. Jeanisch T, Junghanss T, Wills B, Brady OJ, Eckerle I, Farlow A, et al. Dengue expansion in Africa - not recognized or not happening? Emerg Infect Dis. 2014;20:e140487

16. Weaver SC. Urbanization and geographic expansion of zoonotic arboviral diseases: mechanisms and potential strategies for prevention. Trends Microbiol. 2013;21:360-3.

17. Huang YJS, Higgs S, Horne KME, Vanlandingham DL. Flavivirus-mosquito interactions. Viruses. 2014;6:4703-30.

18. Konan YL, Coulibaly ZI, Koné AB, Ekra KD, Doannio JM-C, Dosso M, et al. Species composition and population dynamics of Aedes mosquitoes, potential vectors of arboviruses, at the container terminal of the autonomous port of Abidjan, Côte d'Ivoire. Parasite. 2013;20:13.
19. Cordellier R, Bouchite B, Roche J-C, Monteny, Diaco B, Akoliba P. The sylvatic distribution of dengue 2 virus in the subsudanese savanna areas of Ivory Coast in 1980. Entomological data and epidemiological study. Cah ORSTOM Entomol Med Parasit. 1983:21:165-79.

20. Durand JP, Vallée L, de Pina JJ, Tolou H. Isolation of a dengue type 1 virus from a soldier in West Africa (Côte d'Ivoire). Emerg Infect Dis. 2000;6:83-4.

21. Meng LM, Tomohiko T, Akira K, Shigeru T, Chang-Kweng L, Mitsuo S, et al. Importation of dengue virus type 3 to Japan from Tanzania and Côte d'Ivoire. Emerg Infect Dis. 2010;16:1770-2.

22. Koné AB, Konan YL, Coulibaly ZI, Fofana D, Guindo-Coulibaly N, Diallo M, et al. Entomological evaluation of the risk of urban outbreak of yellow fever in 2008 in Abidjan, Côte d'Ivoire. Med Sante Trop. 2013;23:66-71. http://www. ncbi.nim.nih.gov/pubmed/23693032. Accessed 31 Jan 2016.

23. Cordellier R, Germain M, Hervy JP, Mouchet J. Guide pratique pour l'étude des vecteurs de fièvre jaune en Afrique et méthodes de lutte. 33rd ed. Paris: ORSTOM; 1977. http://www.documentation.ird.fr/hor/fdi:08619. Accessed 17 Feb 2016.

24. Cornet M, Dieng PL, Valade M. Note sur l'utilisation des pondoirs-pièges dans les enquêtes sur les vecteurs selvatiques de fièvre jaune. Cah ORSTOM Ser Entomol Med Parasitol. 1978;16:309-14. www.documentation.ird.fr/hor/ fdi:19163. Accessed 16 Feb 2016.

25. Juliano SA, O'Meara GF, Morill JR, Cutwa MM. Desiccation and thermal tolerance of eggs and the coexistence of competing mosquitoes. Oecologia. 2002;13:458-69.

26. O'Neal PA, Juliano SA. Seasonal variation in competition and coexistence of Aedes mosquitoes stabilizing effects of egg mortality or equalizing effects of sources? J Anim Ecol. 2013;82:256-65.

27. Sylla M, Ndiaye M, Black IV C. Aedes species in treeholes and fruit husks between dry and wet seasons in southeaster Senegal. J Vector Ecol. 2013; 38:237-44.

28. Piovezan R, Rosa L, Rocha ML, de Azevedo TS, Von Tuben CJ. Entomological surveillance, spatial, and diversity of Culicidae (Diptera) immatures in rural area of the Atlantic forest biome, State of São Paulo, Brazil. J Vector Ecol. 2013;38:317-25.

29. McClelland GAH. A worldwide survey of variation in scale pattern of the abdominal tergum of Aedes aegypti (L.) (Diptera: Culicidae). Trans R Entomol Soc Lond. 1974;126:239-59.

30. Brown JE, Evans BR, Zheng W, Obas V, Barrera-Martinez L, Egizi A, et al. Human impacts have shaped historical and recent evolution in Aedes aegypti, the dengue and yellow fever mosquito. Evolution. 2014;68:514-25.

31. Brown JE, McBride CS, Johnson P, Ritchie S, Paupy C, Bossin H, et al. Worldwide patterns of genetic differentiation imply multiple 'domestications' of Aedes aegypti, a major vector of human diseases. Proc R Soc B. 2011:278:2446-54.

32. Mattingly PF. Genetical aspects of the Aedes aegypti problem, II. Disease relationships, genetics and control. Ann Trop Med Parasitol. 1958:52:5-17.

33. Tabachnick WJ. Evolutionary genetics and insect borne disease. The yellow fever mosquito, Aedes aegypti. Am Entomol. 1991;37:14-24.

34. Diawara A, Yoroba F, Kouadio KY, Kouassi KB, Assamoi EM, Diedhiou A, et al. Climate variability in the sudano-guinean transition area and its impacts on vegetation: the case of the Lamto region in Côte d'Ivoire. Adv Meteorol. 2014;ID831414:1-11. www.hindawi.com/journals/amete/2014/831414/. Accessed 15 Feb 2016.

35. Repeated measures analysis with Stata. http://www.ats.ucla.edu/stat/stata/ seminars/repeated_measures/repeated_measures_analysis_stata.htm. Accessed 13 Mar 2016.

36. WHO. Guidelines for laboratory and field testing of mosquito larvicides. WHO/CDS/WHOPES/GCDPP/2005.13. 2005.

37. Harbach R. The Culicidae (Diptera): a review of taxonomy, classification and phylogeny. Zootaxa. 1668;2007:1-766.

38. Weaver W, Shannon CE. The mathematical theory of communication. Urbana: University of Illinois; 1949.

39. Simpson EH. Measurement of diversity. Nature. 1949;163-8. doi:10.1038/ 163688a0.

40. Diallo D, Sall AA, Buenemann M, Chen R, Faye O, Diagne CT, et al. Landscape ecology of sylvatic chikungunya virus and mosquito vectors in southeastern Senegal. PLoS Negl Trop Dis. 2012;6:e1649.

41. Guindo-Coulibaly N, Adja AM, Koudou GB, Konan YL, Diallo M, Koné AB, et al. Distribution and seasonal variation of Aedes aegypti in the health district of Abidjan (Côte d'Ivoire). Eur J Sci Res. 2010;40:522-30. 
42. Raharimalala FN, Ravaomanarivo LH, Ravelonandro P, Rafarasoa LS, Zouache K, Tran-Van V, et al. Biogeography of the two major arbovirus mosquito vectors, Aedes aegypti and Aedes albopictus (Diptera, Culicidae), in Madagascar. Parasit Vectors. 2012;5:56.

43. Diallo D, Diagne C, Hanley KA, Sall AA, Buenemann M, Ba Y, et al. Larval ecology of mosquitoes in sylvatic arbovirus foci in southeastern Senegal. Parasit Vectors. 2012;5:286.

44. Serpa LLN, Marques GRAM, de Lima AP, Voltolini JC, Arduino MB, Barbosa $\mathrm{GL}$, et al. Study of the distribution and abundance of the eggs of Aedes aegypti and Aedes albopictus according to the habitat and meteorological variables, municipality of São Sebastião, São Paulo State, Brazil. Parasit Vectors. 2013;6:321.

45. Tsuzuki A, Duoc T, Higa Y, Nguyen TY, Tahagi. Effect of peridomestic environments on repeated infestation by preadult Aedes aegypti in urban premises in Nha Trang City, Vietnam. Am J Trop Med Hyg. 2009;81:645-50.

46. Hayden MH, Uejio CK, Walker K, Ramberg F, Moreno R, Rosales C, et al. Microclimate and human factors in the divergent ecology of Aedes aegypti along the Arizona, US/Sonora, MX border. Ecohealth. 2010;7:64-77.

47. Mweya CN, Kimera SI, Mellau LSB, Mboera LEG. Inter-epidemic abundance and distribution of potential mosquito vectors for Rift Valley fever virus in Ngorongoro district, Tanzania. Glob Health Action. 2015;8:25929.

48. Arduino MB. Assessment of Aedes aegypti pupal productivity during the dengue vector control program in a coastal urban centre of São Paulo state, Brazil. J Insect. 2014;ID301083:1-9.

49. Yee DA, Abuzeineh AA, Ezeakacha NF, Schelble SS, Glasgow WC, Flanagan SD, et al. Mosquito larvae in tires from Mississippi, United States: the efficacy of abiotic and biotic parameters in predicting spatial and temporal patterns of mosquito populations and communities. J Med Entomol. 2015; doi: http://dx.doi.org/10.1093/jme/tjv028 .

50. Koenraadt CJ, Harrington LC. Flushing effect of rain on container-inhabiting mosquitoes Aedes aegypti and Culex pipiens (Diptera: Culicidae). J Med Entomol. 2008;45:28-35.

51. Konan YL, Fofana D, Coulibaly A, Diallo AB, Doannio JMC, Ekra KD, et al. Entomological investigations conducted around ten cases of yellow fever in 2009 in the Denquélé sanitary region, Côte d'Ivoire. Bull Soc Pathol Exot. 2011;104:296-302.

52. Cox J, Grillet ME, Ramos OM, Amador M, Barrera R. Habitat segregation of dengue vectors along an urban environment gradient. Am J Trop Med Hyg. 2007:76:820-6.

53. Meideiros-Sousa AR, Ceretti-Junior W, de Carvalho GC, Nardi MS, Nardi MS, Araujo $A B$, et al. Diversity and abundance of mosquitoes (Diptera: Culicidae) in urban park: Larval habitats and temporal variation. Acta Trop. 2015;150: 200-9.

54. Adebote AD, Oniye JS, Ndams SI, Nache KM. The breeding sites of mosquitoes (Diptera: Culicidae) in peridomestic containers and implication in yellow fever transmission in villages around Zaria, northern Nigeria. J Entomol. 2006;3:180-8

55. Harrington LC, Fleisher A, Ruiz-Moreno D, Vermeylen F, Wa CV, Poulson RL, et al. Heterogeneous feeding patterns of the dengue vector, Aedes aegypti, on individual human hosts in rural Thailand. PLoS Negl Trop Dis. 2014;8: e3048.

56. Waever ST, Takken W. Feeding strategies of anthropophilic mosquitoes result in increased risk of pathogen transmission. Trends Parasitol. 2012;28: 114-21.

57. Van Somerren ECCTC, Furlong M. The mosquitoes of Kenya coast; records of occurrence, behavior and habitat. Bull Entomol Res. 1955;46:463-93.

58. Powell JR, Tabachnick. History of domestication and spread of Aedes aegypti - a review. Mem Inst Oswaldo Cruz. 2013;108:11-7.

59. Tabachnick WJ, Powell JR. A world-wide survey of survey of genetic variation in the fever mosquito, Aedes aegypti. Genet Res. 1979;34:215-29.

60. Komono BD. La fievre jaune en Côte d'Ivoire. Historique, actualité et perspectives de recherche pour la lutte. Med Afr Noire. 2012;5910:459-69.

61. Rapley LP, Johnson PH, Williams CR, Silcock RM, Larman M, Long SA, et al. A lethal ovitrap-based mass trapping scheme for dengue control in Australia: II. Impact on populations of the mosquito Aedes aegypti. Med Vet Entomol. 2009;23:303-16.

62. Mackay AJ, Amador M, Barrera R. An improved autocidal gravid ovitrap for the control and surveillance of Aedes aegypti. Parasit Vectors. 2013;6:225.

\section{Submit your next manuscript to BioMed Central and we will help you at every step:}

- We accept pre-submission inquiries

- Our selector tool helps you to find the most relevant journal

- We provide round the clock customer support

- Convenient online submission

- Thorough peer review

- Inclusion in PubMed and all major indexing services

- Maximum visibility for your research

Submit your manuscript at www.biomedcentral.com/submit
Biomed Central 